\title{
Mucor racemosus IgA Measurement
}

National Cancer Institute

\section{Source}

National Cancer Institute. Mucor racemosus IgA Measurement. NCI Thesaurus. Code C130097.

A measurement of the Mucor racemosus IgA in a biological specimen. 